\title{
APLICAÇÃO DE MODELOS \\ MatemÁticos aO Diagnóstico \\ MÉdico, TeCNOLOGIA dE \\ ENGENHARIA E GEOFÍSICA
}

\author{
HELMUT MORITZ \\ (Universidade de Tecnologia de Graz, Graz, Austria)
}

$\mathrm{E}$

m ciência, tecnologia e medicina, as pessoas constantemente confrontam-se com a necessidade de interpretar medidas. Tal interpretação é particularmente difícil em geofísica, medicina e astrofísica. A questão, aqui, é determinar, com base nos dados medidos, parâmetros tais como densidade de massa (no ponto $\mathrm{x}$ ) ou condutividade elétrica $(\mathrm{x})$, que não podem ser medidos diretamente. Tais problemas são, em resumo, chamados inversos. Em medicina e tecnologia, freqüentemente usa-se o termo diagnóstico. Mesmo o processo de percepção sensorial nos homens e nos animais pode ser considerado um problema inverso, no qual conhecimento inequívoco pode ser obtido através de certa redundância (por exemplo, visão, audição e tato). Instrumentos poderosos, ao lado de supercomputadores, ampliam muito a gama da percepção humana e exigem a solução matemática e numérica de uma outra classe de problemas inversos. Estes podem ser considerados entre os mais urgentes dentro das pesquisas matemáticas, embora sua importância só tenha sido reconhecida de forma muito lenta.

Em 1902, o matemático francês J. Hadamard postulou que, para um problema matemático corresponder à realidade, as seguintes condiçóes básicas deveriam ser satisfeitas:

- a solução deve existir (existencia);

- a solução deve ser determinada pelos dados de forma única (unicidade);

- a soluçáo deve depender dos dados de forma contínua (estabilidade).

De fato, essas exigências correspondem ao determinismo ideal da mecânica clássica, que encontrou sua expressão clássica no demônio de Laplace (1740-1827): conhecendo as equaçōes diferenciais da física e, 
como condiçóes iniciais, o estado do universo (que se supóe seja exatamente mensurável e esteja disponível para o demônio), em um certo instante $t=0$, o demônio altamente inteligente poderia calcular com exatidão o estado do universo em qualquer instante t posterior.

Esse determinismo ideal esteve sob ataque por diversas razóes: a causalidade foi questionada pela mecânica quântica $\mathrm{e}$ a dependência contínua com relação às condiçōes iniciais (estabilidade) mostrou ser problemática, mesmo para casos relativamente simples de mecânica celeste, como foi bem demonstrado pela teoria geral da dinâmica não-linear (popularmente conhecida por teoria do caos).

Durante as últimas décadas, têm-se percebido que um número crescente de questōes matemáticas de relevância física são problemas formulados impropriamente (com freqüência chamados problemas mal formulados), os quais não satisfazem um (ou mais) dos critérios acima. Nesse grupo estão questôes que dizem respeito à interpretação de dados medidos.

A expressão problemas impropriamente formulados pode ter sido, de início, entendida como de natureza algo pejorativa. Hoje, no entanto, tornou-se outra, livre de valoração emocional, designando um campo matemático que está atraindo cada vez mais a atenção tanto da matemática pura como da aplicada. Tem se tornado, frequientemente, sinônimo de problemas inversos.

Para introduzir o tema, escolherei aqui um modelo matemático conceitualmente simples: sistemas de equaçöes lineares algébricas. Assim, nosso protótipo simples será um sistema de equaçóes lineares de forma matricial

$$
\text { A } f=\mathbf{g}
$$

em que A é uma matriz dada, $g$ um vetor dado e $f$ um vetor desconhecido de parâmetros do sistema. Se a matriz A é quadrada e regular, então a inversão

$$
f=\mathrm{A}-\mathbf{l g}
$$

existe e fornece um vetor $f$ unicamente definido. Se a matriz é retangular, então pode haver tanto infinitas como nenhuma soluçáo sequer. Ainda assim, a equação $f=\mathrm{A}-1 \mathrm{~g}$ pode existir. Nesse caso, a matriz A-1 é chamada matriz inversa generalizada, a qual, no entanto, não é geralmente estável nem definida unicamente. Tais situaçóes, correspondendo a uma matriz retangular $\mathrm{A}$, são a estrutura matemática típica de muitos 
problemas inversos. $O$ caso pode também corresponder a um problema sobredeterminado, no qual existem mais equaçōes que incógnitas. Tais casos sáo típicos do ajuste de erros de medida, para o qual existem métodos estatísticos padrão de estimativa (mínimos quadrados etc.).

Nossos problemas inversos, no entanto, são usualmente do tipo subdeterminado, nos quais existem menos observaçóes que parâmetros desconhecidos. Esse é o caso quando a densidade de massa (no ponto $\mathrm{x}$ ) ou a condutividade elétrica $(x)$ devem ser determinadas. Nesses exemplos, as observações não são suficientes para determinar de forma única os parâmetros desconhecidos. Precisa-se de informaçáo adicional. Esta pode ser muito trivial, por exemplo, no caso de ser preciso determinar empiricamente uma curva a partir de um conjunto de pontos muito próximos. Entăo, a computação da curva se reduz a seu ajuste ou interpolaçâo. Se o espaçamento dos valores medidos é suficientemente denso, a exigência adicional de que a curva deva ser lisa pode ser suficiente para determiná-la de forma praticamente única. Se existirem apenas uns poucos valores medidos, pode entáo haver um número infinito de curvas compatíveis com os valores dados. Assim, a informação adicional deverá ser muito mais detalhada e específica (por exemplo: a curva deve ser uma reta ou uma senóide).

Todo esquema matemático que produz uma soluçăo única a partir de dados insuficientes deve incorporar alguma informaçáo adicional (ainda que apenas o princípio de mínimos quadrados). Essa é a razão pela qual diferentes algoritmos, aplicados aos mesmos dados, podem dar respostas completamente distintas. Por exemplo, a tomografia sísmica em geofísica é um problema altamente subdeterminado e pode ser semelhante a alguns métodos computadorizados de diagnóstico em medicina. Em problemas comuns de diagnóstico, a informação adicional é dada pela experiência do médico e um bom esquema de diagnóstico deve incorporar considerável experiência médica.

O procedimento é, em princípio, muito simples e adequado. $\mathrm{Na}$ prática, todavia, o perigo aparece quando a informação adicional é insuficiente ou inadequada. Maiores riscos apresenta o caso de um sistema de caixa preta, que fornece belas respostas e diagramas coloridos, mas no qual não se sabe (ou se considera desnecessário saber) que informação foi implicitamente incorporada.

Assim, para um dado método ou técnica que envolva a soluçáo de problemas inversos, devemos ter o cuidado de sempre considerar seus limites de aplicabilidade, bem como as pressuposiçóes conscientes ou inconscientes que fazemos ao aplicá-lo. 
Nosso modelo matemático, extremamente simplificado, já exibiu características gerais importantes dos problemas inversos formulados impropriamente. Em especial, reconhecemos uma importante tarefa: determinar, definir ou tornar consciente a informafäo adicional que está implicita em um dado problema inverso.

Sob outros aspectos, nosso primitivo modelo de sistemas algébricos lineares é bastante inadequado. São necessárias estruturas matemáticas mais sofisticadas: equaçóes diferenciais e integrais, geralmente equaçôes funcionais lineares e não-lineares, bem como métodos espectrais e outras técnicas.

Uma conseqüência infeliz do desenvolvimento incrivelmente veloz da ciência e da tecnologia é que os diferentes campos científicos tendem a perder contato entre si. Poucos cientistas estáo atentos aos desenvolvimentos que acontecem em campos científicos vizinhos. As leis da física, que valem para geofísica, astronomia, tecnologia, química, biologia, medicina etc., fornecem um caráter unificador. Isso não quer dizer que todas as leis da biologia ou mesmo do pensar e do comportamento humano se reduzam à física, mas apenas que os processos físicos nos animais são governados pelas mesmas leis e processos que regem a natureza inorgânica. Em particular, as equaçóes diferenciais da física matemática também descrevem os processos que ocorrem dentro do corpo humano.

A maior parte da informação adicional é obtida por experimentos em condiçóes de laboratório. Nestes, muitos parâmetros podem ser mantidos constantes e, dessa forma, os processos podem ser controlados. Por isso, sistemas tecnológicos atingiram um alto nível de sofisticação e a identificaçáo por sistemas desenvolveu-se muito. Pode-se esperar para o futuro resultados de longo alcance em teoria inversa, com consequiências para nosso conhecimento da natureza, ou seja, para a questão de em que medida sistemas naturais complexos podem ser descritos por dados obtidos a partir de mediçóes.

Para um matemático, problemas inversos raramente são fáceis: comumente difíceis, às vezes insolúveis, mas sempre fascinantes. Mas náo nos esqueçamos da relevância para a vida real: a vida de um paciente pode literalmente depender da possibilidade de ele passar por um raio-X ou por uma tomografia de ressonância magnética nuclear e da confiabilidade dos resultados desses exames. Exploraçáo geofísica - pesquisa por minerais ou depósitos de petróleo - exige a soluçáo de problemas inversos em sismologia, gravimetria e eletromagnetismo. $\mathrm{E}$ urgente um enfoque interdisciplinar. 